Discourse and Communication for Sustainable Education, vol. 8, no. 1, pp. 5-18, 2017

\title{
Tablet Nuff but Life Still Rough: Technology for Early Childhood Sustainable Development in Jamaica
}

\author{
Suzette Kelly-Williams \\ Shortwood Teachers College, Jamaica \\ Ilene R. Berson and Michael J. Berson \\ University of South Florida, the United States
}

\begin{abstract}
Early childhood education has a role to play in constructing a sustainable society. In particular, increasing global attention has focused on how early childhood may help alleviate poverty among children and their families and promote economic growth. Part of this discourse involves the use of technology as a means to improve the quality of early childhood education and optimize the potential for information and communication technology (ICT) to serve as an agent of development. Jamaica's appropriation of technology as part of the early childhood development agenda has emulated Western notions of success. However, the introduction of technology innovations has cultural implications. This study describes and explains perceptions, beliefs and practices about technology among four early childhood teachers in a Jamaican infant school. The findings consider issues for capacity building, including teacher professional development in Jamaica.
\end{abstract}

Keywords: Jamaica, early childhood, sustainability, ICT4D, teacher professional development.

\section{Introduction}

Early childhood education has an important role to play in education for sustainable development (Ärlemalm-Hagsér, 2014; Elliott, 2010; Hägglund \& Samuelsson, 2009; Pipere, Veisson, \& Salīte, 2015; Salìte, 2015; Samuelsson \& Kaga, 2008; Somerville \& Williams, 2015). A child's early years (birth to age eight) align with critical windows of opportunity that are crucial for development of life skills to address challenges in our changing world (Davis, 2009). In addition to preparing learners to confront the causes and effects of economic, social and ecological problems (Bell, 2016), education for sustainability also honors the 'local.' Despite the globalized context that binds us with others in shared efforts to "eradicate poverty and hunger, restore human dignity and equality, protect the planet, manage natural resources, promote economic prosperity, 
and foster peaceful, just and inclusive societies" (Britto, 2015, p. 3), local cultures, languages, histories and geographies anchor these transformational efforts within the neighborhoods and communities where implementation takes place.

The literature on early childhood education for sustainable development (ESD) suggests an integrated approach to embrace cultural practices and other influences on curriculum decisions (Otieno, 2008; Pearson \& Degotardi, 2009). The early years are important for building cultural identity; hence, communities and their social structures play a powerful role in the success of early childhood care and education programs (Davies et al., 2009; Otieno, 2008). Consequently, ESD situates young children and their teachers as important stakeholders in the sustainable development agenda, and as knowledge is a key driver to achieve improvements in a country's educational and economic outcomes, the early childhood integrated curriculum with emphasis on respect for self, others, and the environment is crucial to these efforts.

Part of the global discussion on the use of technology in early childhood classrooms also focuses on the potential for information and communication technology (ICT) to serve as an agent of development (Sutinen \& Tedre, 2010; Unwin, 2009). Information and communication technologies for development (ICT4D) researchers suggest that ICT has the capacity to improve various aspects of life and may be used to help poor and marginalized people achieve economic growth (Avgerou, 2010; Unwin, 2009). The ICT4D efforts are based on Euro-American notions of development, which promote social economic, or political progress and growth (Selwyn, 2013; Unwin, 2009). Depending on the social, political, and economic contexts within which ICTs are introduced, they have the potential to exacerbate inequalities as well as reduce them. To determine the potentials of ICT in developing countries, Avegerou (2010) examined the cultural implications of technology innovations. ICT in developing countries involves the transfer of diffusion and socially embedded action; this action can either be a progressive or disruptive transformation. In keeping with the progressive transformative action of ICT in developing countries, acknowledgement of what is meaningful in the local context is crucial to the constructive adoption of technology innovations in developing societies (Avegerou, 2010; Selinger, 2009; Unwin, 2009). An understanding of how ICTs can be appropriated to achieve sustainable outcomes may help us design programs to empower disadvantaged communities by situating the ICTs in an environment that will support learning (Selinger, 2009; Unwin, 2009).

\section{The Jamaican Context}

Historically, infant schools in Jamaica are the oldest type of formal schooling for children four to six years old. The infant schools were influenced by the British Infant School model developed by Robert Owen. Formal schooling for young children in the early $19^{\text {th }}$ century focused on children four to six years old in an attempt to get them ready for first grade. While some teachers in the basic school and kindergarten classrooms might not have a teaching diploma, all infant school teachers across the island are trained, and they are expected to be the mentors for their colleagues in neighboring basic schools.

Jennings (2001) describes an authoritarian teaching style in the Caribbean context, and student-centered learning is dissonant with the epistemology of Jamaican teachers and educational practice. This positionality of teacher and student roles is a remnant of 
colonial discourses sustained over time. "Implicit cultural practices are passed down through on the job learning from older to newer teachers and less directly through the reproduction of the larger cultures in which [schools] are located" (Tobin, 2011, p. 4).

Research in early childhood classrooms in Jamaica is in its infancy (Jones, Brown, \& Brown, 2011) even though early childhood education in Jamaica has a rich history dating back to the early 1930's (Daley \& Thompson, 2004). For example, the work of local pioneers, such as Henry Ward and Dudley Grant, influenced the conceptualization of teaching and learning for young children (Daley \& Thompson, 2004). A dream of Ward and Grant was to provide Jamaican children with learning experiences that stimulate their imagination and early literacy skills. Over the years the dreams were translated into various initiatives by the Jamaican government through the auspices of the Ministry of Education (MoE, 2004) and have resulted in the transformation of the early childhood sector.

Early childhood education is a crucial component of Jamaica's national development plan. There is emerging consensus in Jamaica regarding the early years of a child's development as a critical period where educators lay the foundation for the development of members of its society (Planning Institute of Jamaica [PIOJ], 2009). Jamaica's development plans include Vision 2030, which for long term planning recognizes early childhood development as a key strategic area for national development and for short term planning treats this area as a priority for implementation (PIOJ, 2009).

The Jamaican early childhood curriculum framework consists of six desirable learning outcomes for children: wellness, communication, valuing culture, intellectual empowerment, respect for self, others and the environment, and resilience. These learning outcomes are closely related to sustainable development, and the integration of technology has the potential to help children achieve the learning outcomes. For children to achieve the outcomes by the end of the preschool stage, their environment should provide activities and experiences that support their development over time (Dudley Grant Memorial Trust, 2010).

Jamaican education initiatives have invested in human capital to promote substantial returns (Jones et al., 2011). Simultaneously, the nation established an ICT4D Jamaican based network organization to define, promote and facilitate the use of information and communication technology in the development process. ICT4D Jamaica believes that the secret to prosperity for the country lies in the effective use of information for learning and earning (Caribbean Information Society Portal, 2010). Therefore, one of the ICT focus areas for ICT4D Jamaica is capacity building.

A Best Practices Guide for early childhood educators in Jamaica and the Jamaican Early Childhood Commission has fostered the use of technology in classrooms (Early Childhood Commission, 2009), mirroring the increased focus among researchers on strategies to facilitate the integration of technology into young children's learning (Barron et al., 2011; National Association for the Education of Young Children [NAEYC] \& the Fred Rogers Center for Early Learning, 2012; Parette, Quesenberry, \& Blum, 2010; Rideout, 2011). In 2013, the government of Jamaica announced its Tablet in Schools (TIS) pilot project, which aligns with the objectives of Digital Education Services (2014). Digital Education Services provides technological tools and e-Learning solutions to reduce the cost of quality education in Jamaica and the Caribbean.

The tablet computers will be equipped with communication applications (Internet, email, Skype), reference books (Bible, world atlas, Jamaican yellow pages, eBooks), 
news and magazines (National Geographic, BBC, CNN), word processing, and multimedia applications. The provision of up-to-date, cost efficient, and accessible information technology to students and teachers is part of Jamaica's national development goal for a technology-enabled society by 2030. Developmentally appropriate integration of technology in the early childhood classroom can address issues of equity and access; foster inquiry, creativity, and problem solving; and promote children's contact with nature (features of early childhood education for sustainable development).

\section{Theoretical Framework: Socio-Cultural Theory}

The integration of technology in early childhood classrooms differs across countries in light of their implicit cultural beliefs and practices. While European-American philosophies have retained a privileged position in the discourse on best practices in education (Pearson \& Degotardi, 2009) and undervalued diverse cultural practices and beliefs (Tobin, 2011), this research elevates Jamaica's context-specific values as central to the study of early childhood education. We engaged a socio-cultural stance in order to critically assess the potentials of information and communication technology for a middleincome society such as Jamaica. In order to investigate the cultural implications of the technology, Rogoff's socio-cultural theory (1990) was applied to interpret the teachers' perceptions, beliefs and practices about technology. According to Rogoff, individuals' development can be understood only in light of the cultural circumstances of their communities.

\section{Purpose of the Study}

Despite Jamaica's development plans for ESD and ICT4D, there is a paucity of empirical data about Jamaican teachers' integration of technology into young children's learning. According to Orlando (2009):

If we are to properly study teachers' practices mediated by ICT and how and why they change, there is a need to acknowledge aspects such as the role played by social, cultural and institutional representations of ICT, school organization of ICT, other stakeholders, and professional and personal experiences with ICT, as well as teachers' beliefs regarding ICT in their role as a teacher in a school (p. 35).

The purpose of this study was to shed light on teacher beliefs about the role of ICT in enhancing access to quality early childhood education and explore how their implementation strategies align with efforts to promote a sustainable Jamaican society. Our inquiry focused on four early childhood teachers in a Jamaican infant school, and the analysis highlighted locally-situated interpretations and practices with technology that may guide capacity building for teachers as they integrate technology into their early childhood classrooms.

\section{Methodology}

Based on in-depth interviews, the authors investigated four early childhood teachers' epistemology about technology and their related practices. The participating teachers were from a Jamaican infant school in a large metropolitan area, where a number of 
private companies often donated used computers for school computer labs. A three interview series was employed, which included focused life history; details of the experience; and reflection on meaning (Seidman, 2006). After the initial interview, transcripts were analyzed for emerging categories. The second interview of each participant was used to follow up on identified themes. The third interview focused on participants' reflections on the meaning of their experiences with technology for young children's learning.

\section{Participants}

The site selected was Beta Infant School (BIS) ${ }^{1}$ located in Southeast Jamaica. BIS was one of forty schools scheduled to receive Tablet PCs for teachers and students, and training of the teachers for implementation was planned for the fall semester. Children spend two years at this school and then transition into first grade at a primary school (grades one through six). The school is co-ed and boasts an enrollment of 384 four to six year olds. There are five classrooms for five year olds, and each teacher meets the basic qualifications, possessing a diploma in early childhood education from any of the notable teacher education programs on the island. The participating teachers were all experienced educators, with 6-18 years in the classroom.

\section{Findings}

The findings highlight the role of technology as a tool of instruction, culturally specific considerations for technology use, and identified professional development needs for capacity building. Each of these areas of focus contributes to our understanding of how implementation aligns with early childhood education for sustainable development.

\section{Technology as a Tool of Instruction}

First exploratory questionThe technology at BIS included a desktop computer in each class, DVD player, CD player, the teachers' laptops, and a multimedia projector that was shared between classes. The teacher pupil ratio of 1:40 with one or two desktop computers made it challenging for teachers to provide opportunities for student engagement with the technology. As a result, the teachers defaulted to traditional use of the technology for their lessons. The teacher as agent had control over the technology, and the children were passive recipients of knowledge projected from a screen. Some efforts had been made for the children to use search engines to research topics, and videos had also been used to reinforce concepts. The children had opportunities to work with software, but it primarily emphasized drill and skill than the kind of engagement that would lead to critical thinking and discovery learning. In spite of this the teachers asserted that the affordances of additional technological resources would extend opportunities for children's active engagement in their learning. One teacher described the affordances of technology for assessment, differentiated instruction, and children's discovery learning. For example, she suggested that the tablet devices could offer enrichment activities to "top up" the lesson for advanced learners. However, she noted that teachers need

\footnotetext{
${ }^{1}$ This is a pseudonym to protect the confidentiality of the school and its teachers.
} 
additional expertise on how to use technology to address the individualized learning needs of children. Another teacher affirmed:

Technology takes you places. As it concerns my job my work, technology for me means my children will become critical thinkers. They will be able to solve problems; they will be able to make decisions. So if my class decides, "Miss, instead of just reading a story to us, why not let us watch it on YouTube?" They can make decisions; they have choices, which give them some amount of autonomy and let them know that it's not about me so much.

One participant reflected on how technology had great potential to enhance children's learning. She focused more on what technology might offer to support the children's learning and autonomy.

Teaching with technology means no more chalk and talk, no more boring lectures. It's no more teacher-centered; it's no more me-me and what I want, how I want and when I want. It means there are options. It means there is a whole big wide exciting world out there for you to explore.

The teachers described the technology as a tool of instruction that added variety and excitement to lessons. Technology in the classroom enhances students' access to understanding through the use of multi-modal representations of difficult to grasp concepts (Selinger, 2009). A participant noted how she used technology to capitalize on teachable moments with the children.

I have had lessons where I recorded my children with my cell phone and have it played back to them, and they were excited. There are moments when I will see them. I like taking anecdotal records of them, memorable moments for me. For example, I saw two students doing a puppet show on their own; they were just doing a puppet show. We did the ethnic groups, and China was one of them. And they were doing a puppet show on their own in make believe Chinese language, and that was memorable for me. I captured that moment. I remember also a student, who liked banging the desk, and I used it as a teachable moment, and I went for a drum. I realized he liked to bang, so instead of reprimanding him about hitting the desk I used it as a teachable moment and a memorable moment for both of us. I videotaped it, with permission of course because we have a consent form for when we take pictures and videos in the school. I showed the video back to him, and he was speechless.

He was covering his face the entire time because he could not believe it was him. And it was also an opportunity to say to mommy, "Mommy I captured your son on video, do you want to see what it looks like?" It was a moment for us to have conversation as teacher and parent. The parent responded, "Yes, you know Miss, I really need to buy him that drum because he is gifted in that way." So I use my phone to record them, to play back for them, for them to see themselves what they look like and audibly for them to hear what they sound like.

Several of the teachers aspired to transfer agency from themselves to the children and actively engage children in discovery. They touted the integration of technology as an effective tool to not only maintain children's interest in activities by presenting concepts in novel ways but also support children's journey to explore. 
Children are very hands-on; they love interaction, they love to explore, they love to discover new things and as a result technology provides an avenue for all that to take place. Technology also allows them to be themselves and to help them to understand that nothing is wrong with making mistakes. Technology also excites children, stimulates them and makes them think, and solve problems. So the role of technology for me is one of discovery, excitement, stimulation and fun as it concerns young children and learning as well.

Nonetheless, the teachers' articulation of their enacted practices with technology primarily focused on the transmission and acquisition of knowledge, emphasizing the readiness skills the five year olds needed for transition to first grade. The use of videos and games to reinforce concepts was a common strategy among the participants to enhance children's literacy skills and vocabulary development. The teachers' description of their practices with the technology stressed augmentation of the children's skills to demonstrate mastery on national assessments, including reading readiness (i.e., letter knowledge and phonemic awareness), numeracy, oral language, writing and drawing. The Grade One Individual Learning Profile (GOILP) assessed these foundational skill areas of incoming first grade students; however, the results also were viewed as a comparative measure of the quality of early childhood education across school sites. As a result, the teachers often overemphasized the readiness skills in an attempt to ensure the children's mastery on all sections of the test.

In low and middle income countries with limited technology resources, focusing on basic foundational skills rather than enhancing teaching with digital tools may lead to a poorer learning environment for students and limited use of expensive resources (Selinger, 2009). Given the large teacher pupil ratio in the classroom, the multimedia projector seemed to be the most loved technology because of the visual capabilities during story time and for picture discussion. In this context, student engagement did not refer to the child as agent. The teacher had control over the technology to provide a visual or auditory enhancement to the lesson. This was important for the teachers to be able to ensure that all 35 or 40 children were able to see what was projected, instead of fussing over a picture they had to wait their turn to view.

It was common for Jamaican teachers to create their instructional materials from recyclables. They spent hours making charts from boxes and discarded card board. The teachers believed technology increased their productivity by reducing the time spent on creating charts for the purpose of instruction. As one teacher explained, "Technology makes life easy and takes the hustle and bustle out of teaching." Instead of drawing and coloring pictures for phonics charts, the teachers said they were able to find suitable pictures online and project them for lessons. They also projected pictures to enhance discussions and oral vocabulary development.

One lesson that I can think of was entitled 'Jamaica land of Beauty' and for that lesson I used a multi-media projector to project Jamaica as an island. Even though descriptions were given to the children before this lesson, the expression on their faces when it was projected on the screen they were in awe and they said to me, "Teacher is that really Jamaica?" and I was like, "Yes, this is what Jamaica looks like." Because of the screen and how it is projected and the image as it is shown they were fascinated and they went into their own conversation and one said "I really want to go deer sub man" 
(I would like to visit that place). They were really fascinated seeing a big pictorial view. It wasn't small in the book; it wasn't a little clip art picture that was pasted in their book. It was a big projected screen that showed the beauty of the island.

The descriptions of technology to replace charts positioned the teacher as agent, and the children as passive recipients. The teachers equated student engagement with students' attentiveness and interest in the lesson. The teachers explained that this was due to the limited resources they had available for children to construct their own learning with the technological tools. The lessons often involved watching a video from the DVD player, listening to a story on a CD player, or viewing the visuals from the computer and multimedia projector. The teachers attempted to rotate children for access to the computers in the classrooms, maximizing use through whole and small group instruction. Therefore, the projection of images from the laptop and multimedia projector replicated the traditional lecture method of teaching. The teachers needed support to optimize technology to enhance their teaching and achieve their aspirational goals of active child engagement in learning.

\section{Culturally Specific Considerations for Technology Use}

The teachers' perceptions of technology are grounded in the social context of their school and the wider Jamaican culture. Technology integration in the early childhood classroom is not a common practice among Jamaican teachers. The children at BIS were not accustomed to individual learning tools, and tablet computers for each child would require careful management by the teacher. Jamaican government's TIS project, which aimed to provide individual tablet computers for children and teachers, seemed to align with a Western cultural stance, where individual learning is valued over collective efforts. With the exception of one teacher who owned a Kindle Fire, the teachers had no previous experience with tablet computers. In describing the initiatives from the Ministry of Education, one teacher lamented:

You cannot at all times implement new policies every year or every three
years and expect us to accomplish that when we are working with limited
resources and time. Put some measures in place where you know that some of
the things they want to implement is unrealistic in the sense of the culture of
the children we are working with. While I understand that they want to meet
first world guidelines, millennium goals and so forth, where Jamaica is con-
cerned our culture is different. At the early childhood level, at this institution
I can speak to that without hesitation that we are committed and we will put
in all that needs to be done where our students are concerned and that's the
part that I don't really like, the demands that are placed upon us. We are
physically starved and intellectually drained.

The compatibility of the tablet computers with the current ideas about teaching remained an area of crucial concern. While the teacher as facilitator and guide is the ideal being voiced in educational discourse and national education plans, the reality is that knowledge transmission is the most dominant teaching style of the region (Jennings, 2001). The teachers' tacit understandings of how things should work will certainly be 
challenged with attempts at technology integration. Rogers (1995) asserted that any idea that is incompatible with the values and norms of the social system will not be rapidly adopted by members of that group.

In a cross-national study of early childhood education throughout the Englishspeaking Caribbean, low-income parents viewed good children as academically competent, cooperative, respectful, compliant, and obedient (Roopnanarine \& Metingodan, 2006). The parents preferred more structured, academically-laced instructional approaches and viewed play as frivolous to development. In spite of this, the language of playbased practices has seeped into the early childhood curricula. Jamaican administrators and teachers embrace virtues of child-centeredness and extol the benefits of play and creative activities in engaging children's minds. However, in practice children are given few choices within structured educational settings. It would seem that curriculum designers are attempting to keep up with globalization by adopting Western influences, resulting in an articulated curriculum that is extolled by teachers but is in stark contrast to the actual approaches that teachers adopt in early childhood classrooms.

Although teachers retain the locus of control in using technology, they perceive that the digital tools have facilitated access to culturally relevant learning experiences. One teacher found videos of adult groups performing brukins, the creolized traditional dance that celebrated Jamaica's emancipation from British colonial rule. As the children watched she believed that they became connected to the heritage of Jamaica, and had access to resources that exemplified the nation's motto: "Out of many, one people."

She explained further how she used technology during circle time to have discussions with the children about Jamaican reggae icon, Bob Marley.

I downloaded a stage show where Bob Marley was performing. Yes, and there was also an interview in the same video. The children were able to see Bob Marley, knowing that Bob Marley is no longer alive. They were not just seeing a picture of Bob Marley, but they were seeing him perform on stage. They were able to talk about how he moved, when he is singing, how Bob Marley played the guitar. After that they were able to dramatize and roleplay Bob Marley singing "One Love." The students sang "One Love" and shook their heads. They were able to see pictures of Bob Marley's children, his wife; it was just so beautiful. It was really a powerful moment because the children learned a lot about a man who has contributed so much to Jamaica.

\section{Capacity Building}

Educator capacity building is a critical component to sustain the effective use of technology with children. The four participants were graduates of the same teacher education program. They shared similar knowledge and experiences from college courses, but noted the focus was on gaining familiarity with the technology tools and not acquiring technological pedagogical knowledge to facilitate children's appropriation of technology for their learning.

In addition to their college coursework, the teachers also mentioned that some of their technology skills were self-taught. One participant believed that the onus was on each teacher to achieve personal technology competence. She mentioned that the MOE could provide workshops, but teachers should use their own initiative to seek out techn- 
ology training. In her own quest to ensure that children were gaining useful knowledge and experiences in school to master the skills they need to function in life, she emphasized the importance of reading and doing research to keep up to date with technology in early childhood education.

I do a lot of research; I do a lot of reading. I read plenty of journals. I also connect with the NAEYC [National Association for the Education of Young Children] website and keep abreast with what's happening concerning technology because I believe that as a teacher, I am in Jamaica, and I don't know everything happening out there. So I have to stay connected with the world of technology.

The value teachers place on technology for young children's learning influences their pedagogic choices for integrating technology in the classroom (Barron et al., 2011; NAEYC, 2012). The educators at BIS displayed positive dispositions toward the role of technology to support children's learning and enhance the growth of the next generation of nation builders, a key outcome of the early childhood for sustainable development initiative. However, all four participants agreed that they needed further training and continuous support to enhance their pedagogical practices with technology and integrate the new tablets.

In spite of their lack of experience with tablet computers, the Jamaican government's TIS project motivated the teachers. There was a sense of collective excitement with apprehension as they shared concerns about the resources they had and the tablet computers they were anticipating. The teachers' misgivings were not in resistance to the tablets, but rather they were anxious about their own need for technology training. They identified common issues for implementation, including limited technology resources to accommodate their large class sizes, the challenges of supporting and supervising students given the high teacher-pupil ratios, and unreliable Internet access.

The teachers described some of the challenges they envisioned once the TIS project was launched. Enthusiasm for the tablet computers was mediated by anxiety about how the children would care for the tablets. Technology has the potential to enhance the quantity and quality of educational delivery, but there are also adverse consequences that need consideration (Selinger, 2009). The TIS project would allow children to take home their tablet computers, and the devices would be equipped with location monitoring for tracking. Nonetheless, some of the children throughout Jamaica live in volatile communities with limited social capital. In an attempt to protect the children from being robbed on their way to or from school, the teachers suggested that the local government needs a plan to ensure the safety and wellbeing of the children while building the social capital of the communities in which they live. The plan should address learning with technology as a community initiative before putting an expensive device in the hands of children, which might attract thieves. It would be nalve to not think about the safety of children and teachers with expensive tools in the Jamaican context.

One of the teachers wished they were getting more desktop computers instead of the tablets. She believed the desktop computers would encourage more teamwork than the tablets. She commented:

I would prefer a desktop computer, because it's easier to supervise and better for the children to manage. Better manipulation too, and better team work. On the desktop computer, they learn sharing skills; they learn to take turns. 
The participants identified planning, supervision, and collaboration as important factors in their effective use of technology, especially as it related to the tablet computers. While the teachers identified their personal technology use and training, they also mentioned the implications for the wider school community. The teachers expressed that their colleagues would need to 'get on board' with technology in order for BIS to use the technological resources to capitalize on the affordances for children's learning. The teachers viewed technology integration as a community activity in which all members participated.

Considerations must be made regarding the social context for learning and technology integration. The teachers' anxieties concerning the tablet computers were understandable. The teachers' transition from one computer for forty children to considering one tablet per child created tension. The anxieties reflected a management issue as the teachers contemplated how they would maximize learning with individual tablet computers for forty children. It was also important to consider the cultural view of schooling for Jamaican educators and parents. While the educational discourse acknowledged the teacher as guide and facilitator, the extent to which this ideal is reflected in classroom practices warrants the need for further research.

\section{Way Forward}

This study highlights the centrality of the cultural context of the teachers in shaping their epistemology regarding technology and young children's learning. ICT4D scholars have argued that knowledge about technology cannot be treated as context-free, and that good teaching requires an understanding of how technology relates to the culturallymediated pedagogy and content (Avgerou, 2010; Koehler \& Mishra, 2009; Selinger, 2009; UNESCO, 2013; Unwin, 2009; Iliško \& Ignatjeva, 2014). Thus, providing schools with tablet computers will not automatically transform teachers' practices from knowledge transmission to child centered pedagogy without concomitant attention to capacity building.

To achieve early childhood for sustainable development in Jamaica we need to position teachers with a pedagogical advantage to promote children's learning with technology in their schools, homes, and communities. This initiative requires teachers who are committed and empowered. Moreover, technology practices in the Jamaican classroom are contingent on capacity building and collaboration between researchers and teachers (Davies et al., 2009). By developing a community of practice, the early childhood learning environment may create a sustainable infrastructure to support learning with technology.

Early childhood for sustainable development involves learning as a lifelong process for both teachers and children. Training of teachers should therefore be ongoing to meet the needs of the children and prepare them with skills for their lives outside the classroom walls. Early childhood is a global phenomenon with cultural implications for curriculum, teaching, and children's learning and development (Rogoff, 2003). Given this situated context, it is necessary to identify and use culturally relevant and local resources to enhance teaching and learning in order to prepare the $21^{\text {st }}$ century teacher with critical and problem solving skills for inquiry and innovative practices in Jamaican classrooms. Tobin, Hsueh and Karasawa's (2009) cross-cultural studies of preschools highlighted the challenges of the relationship between continuity and change and the 
influence of importing ideas from abroad. "Preschools are institutions that both reflect and help to perpetuate the cultures and societies of which they are a part" (Tobin et al., 2009 , p. 225). Tobin et al. (2009) contended that culture can act as a source of continuity and as a brake on the impacts of globalization. Educators across nations view early childhood practices differently; there is no universal truth regarding best practices for quality early childhood programs. As such Tobin (2005) encourages the preservation of the cultural practices of schools and guards against throwing out the old for the new in a "one size fits all" approach to early childhood education.

Likewise, the ICT4D research highlights the connections between technological interests and social change (Unwin, 2009). The main focus of ICT4D is on what should be done with technology and how it should be done in the unique context of developing countries (Selinger, 2009; Unwin, 2009). "ICT4D therefore has a profoundly moral agenda" (Unwin, 2009, p. 33), with emphasis placed on the needs of the people who stand to benefit from the technology innovation. Ultimately, the focus is not about the technologies themselves, but how the technology can contribute to the empowerment of communities.

\section{References}

Ärlemalm-Hagsér, E. (2014). Participation as ‘taking part in': Education for sustainability in Swedish preschools. Global Studies of Childhood, 4(2), 101-114.

Avgerou, C. (2010). Discourses on ICT and development. Information Technologies and International Development, 6(3), 1-18, Retrieved from http://eprints.lse.ac.uk/ 35564/

Barron, B., Cayton-Hodges, G., Bofferding, L., Copple, C., Darling-Hammond, L., \& Levine, M. (2011). Take a giant step: A blueprint for teaching children in a digital age. New York, NY: The Joan Ganz Cooney Center at Sesame Workshop. Retrieved from:http://joanganzcooneycenter.org/upload_kits/jgcc_takeagiantstep.pdf.

Bell, D. V. (2016). Twenty-first century education: Transformative education for sustainability and responsible citizenship. Journal of Teacher Education for Sustainability, $18(1), 48-56$.

Britto, P. (2015, October 22). Why early childhood development is the foundation for sustainable development [Web log post]. Retrieved from https://blogs.unicef.org/ blog/why-early-childhood-development-is-the-foundation-for-sustainabledevelopment/

Caribbean Information Society Portal. (2010). ICT4D Jamaica. Retrieved from: http://www.carib-is.net/stakeholders/ict4d-jamaica

Daley, M., \& Thompson, J. (2004). The early childhood movement in Jamaica: Building blocks for the future. Kingston, Jamaica: Chalkboard Press.

Davies, J., Engdahl, I., Otieno, L., Pramling-Samuelson, I., Siraj-Blatchford, J., \& Vallabh, P. (2009). Early childhood education for sustainability: Recommendations for development. International Journal of Early Childhood, 41(2), 113-117.

Digital Education Services. (2014). Tablets in schools (TIS) project. Retrieved from http://digedusrv.com/index.php/e-learning/e-learning-in-jamaica/tis-project

Dudley Grant Memorial Trust. (2010). The Jamaica early childhood curriculum guide: Four and five getting ready for life. Kingston, Jamaica: University of the West Indies. Retrieved from http://www.open.uwi.edu/caribecd/multimedia-resources 
Early Childhood Commission, Jamaica [ECC]. (2009). Standards for early childhood institution. Retrieved from http://www.ecc.gov.jm/

Elliott, S. (2010). Essential, not optional: Education for sustainability in early childhood centers. Exchange, 34-37.

Hägglund, S., \& Samuelsson, I. P. (2009). Early childhood education and learning for sustainable development and citizenship. International Journal of Early Childhood, 41(2), 49-63.

Iliško, Dz. \& Ignatjeva, S. (2014). E-learning and education for sustainability. In Ulisses Miranda Azeiteiro, Filho, W. L. \& Caeiro, S. (Ed.). Environmental Education, Communication and Sustainability series, (pp. 167-185), Frankfurt am Main: Peter Lang.

Jennings, Z. (2001). Teacher education in selected countries in the commonwealth Caribbean: The ideal of policy versus the reality of practice. Comparative Education, $37(1), 107-134$.

Jones, J., Brown, A., \& Brown, J. (2011). Caring and learning together: A case study of Jamaica. Early Childhood and Family Policy Series, 21, 1-85. Retrieved from http://www.unesco.org/new/en/media-services/single-view/news/caring_and_ learning_together_a_case_study_of_jamaical

Ministry of Education, Jamaica. (2004). Overview of the education technology resource centre. Retrieved from http://www.moec.gov.jm/overview_of_the_education_ technology-resource_centre.shtml

National Association for the Education of Young Children [NAEYC]. (2012). Technology and young children - ages 3 through 8: A joint position statement of the National Association for the Education of Young Children and Fred Rogers Center for Early Learning and Children's Media. Washington, DC. Retrieved from http://www.naeyc.org/files/naeyc/PS_technology_WEB.pdf

Orlando, J. (2009). Understanding changes in teachers' ICT practices: A longitudinal perspective. Technology, Pedagogy, and Education, 18(1), 33-44.

Otieno, L. (2008). Cultural considerations in early childhood education for sustainable development through traditional culture. In I. P. Samuelsson \& Y. Kaga (Eds.), The contribution of early childhood education to sustainable society (pp. 93-97). Paris, France: UNESCO.

Parette, H. P., Quesenberry, A. C., \& Blum, C. (2010). Missing the boat with technology usage in early childhood settings: A $21^{\text {st }}$ century view of developmentally appropriate practice. Early Childhood Education Journal, 37, 335-343.

Pearson, E., \& Degotardi, S. (2009). Education for sustainable development in early childhood education: A global solution to local concerns? International Journal of Early Childhood, 41(2), 97-111.

Pipere, A., Veisson, M., \& Salite, I. (2015). Developing research in teacher education for sustainability. Journal of Teacher Education for Sustainability, 17(2), 5-43.

Planning Institute of Jamaica [PIOJ]. (2009). Vision 2030, Jamaica: Key strategies and actions under the national outcomes for years 1-3 (2009-2012). Retrieved from: http://www.pioj.gov.jm/

Rideout, V. (2011). Zero to eight: Children's media use in America. Common Sense Media. Retrieved from: www.commonsensemedia.org/sites/default/files/research/ zerotoeightfinal2011.pdf

Rogers, E. M. (1995). Diffusion of innovations (4 ${ }^{\text {th }}$ ed.). New York, NY: Free Press. 
Rogoff, B. (1990). Apprenticeship in thinking: Cognitive development in social context. New York, NY: Oxford University Press.

Rogoff, B. (1995). Socio-cultural setting, inter-subjectivity, and the formation of the individual. In J. V. Wertsch, P. Río, \& A. Alvarez (Eds.), Sociocultural studies of mind (pp. 139-164). New York, NY: Cambridge University Press.

Rogoff, B. (2003). The cultural nature of human development. New York, NY: Oxford University Press.

Salite, I. (2015). Searching for sustainability in teacher education and educational research: Experiences from the Baltic and Black Sea Circle Consortium for educational research. Discourse and Communication for Sustainable Education, 6, 21-29.

Samuelsson, I. P., \& Kaga, Y. (Eds.). (2008). The contribution of early childhood education to a sustainable society. Paris, FR: UNESCO.

Seidman, I. (2006). Interviewing as qualitative research: A guide for researchers in education and social sciences ( $3^{\text {rd }}$ ed.). New York, NY: Teachers College Press.

Selinger, M. (2009). ICT in education: Catalyst for development. In P. T. H. Unwin (Ed), ICT4D: Information and communication technology for development (pp. 206-248). Cambridge, UK: Cambridge University Press.

Somerville, M., \& Williams, C. (2015). Sustainability education in early childhood: An updated review of research in the field. Contemporary Issues in Early Childhood, 16(2), 102-117.

Sutinen, E., \& Tedre, M. (2010). ICT4D: A computer science perspective. In T. Elomaa, H. Mannila, \& P. Orponen (Eds.), Algorithms and applications (pp. 221-231). Berlin, Germany: Springer-Verlag.

Tobin, J. (2011). Implicit cultural beliefs and practices in approaches to early childhood education and care. Asia-Pacific Journal of Research in Early Childhood Education, 5(1), 3-22. Retrieved from http://www.pecerajournal.com/

Tobin, J., Hsueh, Y., \& Karasawa, M. (2009). Preschool in three cultures revisited: China, Japan, and the United States. Chicago, IL: The University of Chicago Press.

Unwin, P. T. H. (Ed.). (2009). ICT4D: Information and communication technology for development. Cambridge, UK: Cambridge University Press.

Correspondence concerning this article should be addressed to Ilene R. Berson, Department of Teaching and Learning, College of Education, University of South Florida, 4202 East Fowler Avenue, EDU 202, Tampa, Florida 33620, United States. Email: iberson@usf.edu 